\title{
Trimetazidine inhibits cardiac fibrosis by reducing reactive oxygen species and downregulating connective tissue growth factor in streptozotocin-induced diabetic rats
}

\author{
YUNYUE ZHAO $^{1 *}$, SUHUA LI ${ }^{1 *}$, ENXI QUAN ${ }^{2}$, HUI ZHANG $^{3}$, YONGXIANG WU ${ }^{1}$, \\ YANTING LUO ${ }^{1}$, LONG PENG ${ }^{1}$, JIARUI WANG ${ }^{1}$, JIEMING ZHU ${ }^{1}$ and JINLAI LIU ${ }^{1}$ \\ Departments of ${ }^{1}$ Cardiology, ${ }^{2}$ Pharmacy and ${ }^{3}$ Ultrasonography, \\ The Third Affiliated Hospital of Sun Yat-sen University, \\ Guangzhou, Guangdong 510630, P.R. China
}

Received August 28, 2018; Accepted May 16, 2019

DOI: $10.3892 /$ etm.2019.7705

\begin{abstract}
Diabetes may affect myocardial fibrosis through oxidative stress. Trimetazidine (TMZ) is an anti-anginal agent. The present study aimed to determine the modulatory effect of TMZ on reactive oxygen species (ROS) and connective tissue growth factor (CTGF) expression and to evaluate the potential of TMZ to improve diastolic function in streptozotocin (STZ)-induced diabetic rats. After treating STZ-induced diabetic rats with TMZ for 16 weeks, a decrease in malondialdehyde levels, cardiac collagen volume fraction, left ventricular (LV) end-diastolic pressure and protein expression of collagen-I (Col I), Col III and CTGF compared with those in diabetic control rats was observed. In vitro, TMZ inhibited Col I, Col III and CTGF protein expression in cardiac fibroblasts treated with high glucose and decreased intracellular ROS generation and hydroxyproline content in the cell culture medium of cardiac fibroblasts. TMZ markedly improved cardiac fibrosis and diastolic function in diabetic rats. This effect was associated with a reduction in ROS production and CTGF expression in cardiac fibroblasts. The present study suggests that TMZ may be beneficial for protecting the hearts of diabetic patients.
\end{abstract}

\section{Introduction}

Diabetes mellitus (types I and II) affect multiple organ systems and result in numerous complications, including

Correspondence to: Professor Jinlai Liu, Department of Cardiology, The Third Affiliated Hospital of Sun Yat-sen University, 600 Tian-he Road, Guangzhou, Guangdong 510630, P.R. China E-mail: liujlgz@yeah.net

${ }^{*}$ Contributed equally

Key words: reactive oxygen species, cardiac fibrosis, connective tissue growth factor, trimetazidine, diabetic rat myocardial fibrosis (1). Cardiac fibrosis is a significant factor causing cardiac systolic and diastolic dysfunction (2). However, treatment targeting cardiac fibrosis is rare. Cardiac fibrosis has been identified as the key regulator of cardiac remodeling. Interstitial fibroblast proliferation and excessive extracellular matrix are the major characteristics of cardiac fibrosis (3). High glucose (HG) or hyperglycemia, the major characteristic of diabetes, has been demonstrated to induce collagen secretion and proliferation of cardiac fibroblasts (CFs) and to increase oxidative stress $(4,5)$.

Connective tissue growth factor (CTGF) is a pro-adhesive matricellular protein associated with numerous diabetic complications (6), including diabetic cardiomyopathy. The role of CTGF in the pathogenesis of fibrosis in tissue has been the major focus of studies on diabetes by our and other groups (7-9). The induction of CTGF by oxidative stress has been demonstrated in various studies (10-12).

Trimetazidine (TMZ), an anti-anginal agent, selectively inhibits the activity of mitochondrial long-chain 3-ketoacyl-CoA thiolase, resulting in inhibition of free fatty acid (FFA) oxidation and promotion of glucose oxidation (13). In addition to metabolic effects, studies have indicated that TMZ exerts cardioprotective effects by reducing oxidative damage, inhibiting inflammation and apoptosis, and improving endothelial function (14-16).

Thus, it was hypothesized that TMZ reduces oxidative stress and downregulates the expression of CTGF in CFs, leading to improvement of hyperglycemia-induced cardiac fibrosis. The present study was conducted to assess whether TMZ treatment can reduce collagen secretion and induce changes in CTGF expression in vitro and in vivo by western blotting and pathological test experiments.

\section{Materials and methods}

Animal model preparation. Male Sprague Dawley (SD) rats (age, 6 weeks; weight, 160-200 g) were obtained from the Animal Department of Sun Yat-Sen University. A total of 40 rats were randomly subdivided into two groups: A normal 
control group $(\mathrm{N})$, consisting of normal rats $(n=10)$, and a diabetic group, consisting of streptozotocin (STZ)-treated rats $(n=30)$. Diabetes was induced by a single intraperitoneal (i.p.) injection of STZ at a dose of $45 \mathrm{mg} / \mathrm{kg}$ in $0.1 \mathrm{M}$ citrate-buffered saline ( $\mathrm{pH} 4.4)$, while the normal rats ( $\mathrm{N}$ group) were injected with an equal volume of $0.1 \mathrm{M}$ citrate buffer. Fasting blood glucose was tested at 1 week after the injection using a glucometer (Accu-chek ${ }^{\circledR}$ Performa; Roche Diagnostics), and rats with a blood glucose level of $16.7 \mathrm{mM}$ or higher were considered diabetic. A total of four STZ-treated rats died due to the toxicity of STZ, whereas three STZ-treated rats failed to develop diabetes. The dose of STZ used and mortality rate observed in the present study were comparable with that of a previous study (17). Rats that successfully developed diabetes were randomly subdivided into two groups: A diabetic control group (C group, $\mathrm{n}=12$ ), which received normal saline (NS) by oral gavage, and a diabetes + TMZ group (TMZ group), which received NS + TMZ $(15 \mathrm{mg} / \mathrm{kg} /$ day $)$ by oral gavage for 16 weeks $(n=11)$. Rats in the $N$ group $(n=10)$ received NS by oral gavage in the same timeframe. At the end of the experiment, the final body weight of these rats was recorded, and the rats were subjected to the tests described below. A total of 5 rats died while under anesthesia for hemodynamic testing ( 1 in the $\mathrm{N}$ group, 2 in the $\mathrm{C}$ group and 2 in the TMZ group). In the present study, none of the rats lost weight by $>20 \%$. The left ventricular (LV) free wall was fixed with $4 \%$ paraformaldehyde, and the remaining samples were stored in liquid nitrogen. The total heart (TH) and LV weights (LVW) were recorded.

Echocardiography (ECG) measurements. The device used was a high-resolution small animal ultrasonic imaging system (Visual Sonics) with a frequency of $30 \mathrm{MHz}$. The test was performed after drug treatment for 16 weeks. Prior to testing, each rat was anesthetized with a diethyl ether mask and had its chest fur shaved. The data were collected in the middle short section of the papillary muscle by two-dimensional ECG and M-type ECG. The parameters included systolic LV posterior wall thickness (LVPW-s), diastolic LV posterior wall thickness (LVPW-d), LV ejection fraction (LVEF), LV fractional shortening (LVFS) and early diastolic mitral valve blood flow velocity E peak/late diastolic mitral valve blood flow velocity A peak (E/A).

Hemodynamic measurements. The rats were anesthetized with $1.25 \%$ tribromoethanol (250 mg/kg i.p.). Surgery was performed to assess the hemodynamic data as described previously $(18,19)$. A microtip pressure transducer catheter (3.5 Fr; Millar Instruments, Inc.) was introduced via the right carotid artery into the $\mathrm{LV}$. The heart rate, $\mathrm{LV}$ end-systolic pressure (LVESP), LV end-diastolic pressure (LVEDP), and the maximum rates of increase and decrease in $\mathrm{LV}$ pressure $( \pm \mathrm{dp} / \mathrm{dt})$ were measured using a commercially available analog-to-digital converter and analyzed using the AcqKnowledge software (version 4.2.0; BIOPAC Systems, Inc.).

Exhaustion swimming exercise test. The exhaustion swimming exercise test was performed to assess exercise capacity according to a method previously described (20).
Histological analysis. After the hemodynamic measurements were performed, all rats were euthanatized by cardiac exsanguination under anesthesia. Euthanasia was confirmed by removing the heart. Hearts were washed in cold $\left(4^{\circ} \mathrm{C}\right)$ saline solution $(\mathrm{NaCl} 0.9 \%)$. The LVs of the rats were fixed with $4 \%$ paraformaldehyde for $24 \mathrm{~h}$ and were then embedded in paraffin. Sections $(6 \mathrm{~mm})$ were stained with Masson's trichrome to detect collagen. To examine the degree of cardiac fibrosis, 5 fields were randomly selected and the cardiac collagen volume fraction (CVF) was computed as the ratio of the Masson's trichrome-stained fibrosis area to the total area of the myocardium using Image-Pro-plus 5.0 software (Media Cybernetics). Sections stained with $\mathrm{H} \& \mathrm{E}$ were also analyzed under a microscope (Axio Imager.Z2; Zeiss AG).

Hydroxyproline and malondialdehyde (MDA) measurement. The concentrations of hydroxyproline (cat. no. A030-2-1) and MDA (cat. no. A003-1-2) in myocardial tissue were detected using commercial kits (Nanjing Jiancheng Bioengineering Institute) in accordance with the manufacturer's protocols.

Cell culture. CFs were isolated and cultured from 1-3 day old neonatal SD rats obtained from the Sun Yat-Sen University Experimental Animal Center (12). The cells were cultured in Dulbecco's modified Eagle's medium (Gibco; Thermo Fisher Scientific, Inc.) containing $10 \%$ fetal bovine serum (FBS; Gibco; Thermo Fisher Scientific, Inc.). The cells were cultured in a $5 \% \mathrm{CO}_{2}$ incubator under a humidified atmosphere at $37^{\circ} \mathrm{C}$. All cell experiments were performed with $\mathrm{CFs}$ at passages 2-3. CF phenotype was verified using immunofluorescence staining in a protocol previously described by Fan et al (21). Briefly, cells were incubated with FBS, aforementioned, followed by incubation with primary antibodies against vimentin (1:200; cat. no. v6389; Sigma-Aldrich; Merck $\mathrm{KGaA}$ ) and von Willebrand factor (1:200; cat. no. HPA001815; Sigma-Aldrich; Merck KGaA) overnight at $4^{\circ} \mathrm{C}$ in humidified chamber. Following further washing with PBS, cells were incubated with a mixture of two secondary antibodies (fluorescein-conjugated anti-mouse IgG; 1:500; sc516140; Santa Cruz Biotechnology, Inc. and Texas Red ${ }^{\circledR}$-conjugated goat anti-rabbit IgG, 1:1,000; ab6719; Abcam) for $1 \mathrm{~h}$ at room temperature in the dark. Following another wash with PBS, cells were incubated with 300 nM DAPI (Invitrogen; Thermo Fisher Scientific, Inc.) for $1 \mathrm{~min}$ at room temperature. Cells were subsequently rinsed again with PBS and mounted with an aqueous mounting medium. The stained cells were visualized using a fluorescence microscope (magnification, x200). For the experiments, CFs that were grown to $80 \%$ confluence and that were serum-starved in serum-free medium for $24 \mathrm{~h}$ prior to treatment were used. To detect the direct effects of TMZ on myocardial collagen formation, CFs were subjected to the following treatment regimens: DMEM with $5.6 \mathrm{mM}$ glucose, designated thereafter as the normal glucose (NG) group; DMEM with $25 \mathrm{mM}$ glucose, designated as the high glucose $(\mathrm{HG})$ group and $\mathrm{HG}+$ varying concentrations of TMZ $(0.1,1$ and $10 \mu \mathrm{M})$ for up to $24 \mathrm{~h}$. Collagen synthesis was assayed using western blot analysis.

Western blot analysis. Total cell proteins and LV tissues were prepared in radioimmunoprecipitation assay lysis buffer 
(Beyotime Institute of Biotechnology) in accordance with the manufacturer's protocol. Protein concentrations were determined using Bicinchoninic Acid assay. Equal amounts of protein $(40 \mu \mathrm{g})$ were separated by $10 \%$ SDS-PAGE and then transferred to a polyvinylidene difluoride membrane (Thermo Fisher Scientific, Inc.). The membrane was blocked in 5\% nonfat milk for $1 \mathrm{~h}$ at room temperature and was then incubated with following antibodies: CTGF (1:1,000; cat. no. ab6992; Abcam), collagen III (Col III; 1:8,000; cat. no. ab7778; Abcam), collagen I (Col I; 1:1,000; cat. no. 84336; Cell Signaling Technology, Inc.) and superoxide dismutase 2 (SOD2; 1:5,000; cat. no. ab13533; Abcam) at $4^{\circ} \mathrm{C}$ overnight. The membranes were incubated with horseradish peroxidase-conjugated mouse anti-rabbit IgG secondary antibody (1:5,000; cat. no. sc-2357; Santa Cruz Biotechnology, Inc.) for $1 \mathrm{~h}$ at room temperature. Protein expression was determined with enhanced chemiluminescence (EMD Millipore; Merck KGaA). The bands were quantitatively evaluated by densitometry using ImageJ software (version 2; National Institutes of Health).

Analysis of intracellular reactive oxygen species (ROS) generation. Cellular ROS accumulation in CFs was measured by using fluorescent probe, dichloro-dihydro-fluorescein diacetate (DCFH-DA; Beyotime Institute of Biotechnology). Cells were incubated with $5 \mu \mathrm{M}$ DCFH-DA for $20 \mathrm{~min}$ at $37^{\circ} \mathrm{C}$. DCF fluorescence was detected by flow cytometry (BD FACSCalibur ${ }^{\mathrm{TM}}$; emission, $480 \mathrm{~nm}$; bandpass filter, 530 nm; BD Biosciences). For each sample, 10,000 events were collected. ROS production was calculated as the mean fluorescence intensity using FlowJo software (version 7.6; FlowJo Software LLC).

Statistical analysis. All data were expressed as the mean \pm standard deviation. Statistical analysis of the data was performed by one-way analysis of variance with a Bonferroni post hoc test. $\mathrm{P}<0.05$ was considered to indicate a statistically significant difference. All calculations were performed with the SPSS software (version 15.0; SPSS, Inc.).

\section{Results}

Effect of TMZ on cardiac structure, cardiac function and exercise capacity in STZ-induced diabetic rats. To observe the influence of hyperglycemia on cardiac structure and function, the dimensions of the LV, cardiac function and hemodynamic parameters we measured by ECG and Millar Instruments. The results of the ECG examination suggested that the LVEF, LVFS and LVPW-d in the C group were lower than those in the $\mathrm{N}$ group $(\mathrm{P}<0.05)$. However, these parameters, were not significantly different between the rats in the $\mathrm{C}$ group and the TMZ group (Table I). Furthermore, the results of the gross pathological analysis revealed that the ratios of LV/TH and LVW/BW were higher in the rats in the $\mathrm{C}$ group than those in the rats in the $\mathrm{N}$ group $(\mathrm{P}<0.05)$. The $\mathrm{LV} / \mathrm{TH}$ was lower in the TMZ group than that in the $\mathrm{C}$ group $(\mathrm{P}<0.05)$. However, there was no significant difference in LVW/BW between the TMZ group and the $\mathrm{C}$ group (Table II). As indicated in Table III, the LVEDP was higher and the $\mathrm{dp} / \mathrm{dt}_{\max }$ was lower in the $\mathrm{C}$ group than those in the $\mathrm{N}$ group $(\mathrm{P}<0.001$ and
Table I. Effect of TMZ on cardiac function measured by color Doppler ultrasound.

\begin{tabular}{llll}
\hline Parameter & $\mathrm{N}(\mathrm{n}=9)$ & $\mathrm{C}(\mathrm{n}=8)$ & $\mathrm{TMZ}(\mathrm{n}=8)$ \\
\hline HR $(\mathrm{bpm})$ & $388 \pm 43$ & $366 \pm 40$ & $355 \pm 53$ \\
E/A & $1.78 \pm 0.34$ & $1.57 \pm 0.33$ & $1.65 \pm 0.29$ \\
LVEF (\%) & $66.6 \pm 4.8$ & $59.4 \pm 4.3^{\mathrm{a}}$ & $58.5 \pm 6.2^{\mathrm{a}}$ \\
LVFS (\%) & $39.1 \pm 4.2$ & $33.5 \pm 4.2^{\mathrm{a}}$ & $32.8 \pm 4.4^{\mathrm{a}}$ \\
LVPW-d (mm) & $2.07 \pm 0.30$ & $1.76 \pm 0.13^{\mathrm{a}}$ & $1.73 \pm 0.19^{\mathrm{a}}$ \\
LVPW-s (mm) & $2.75 \pm 0.26$ & $2.33 \pm 0.29^{\mathrm{a}}$ & $2.37 \pm 0.24^{\mathrm{a}}$ \\
IVS-d (mm) & $1.74 \pm 0.28$ & $1.51 \pm 0.19$ & $1.54 \pm 0.15$ \\
IVS-s (mm) & $2.74 \pm 0.46$ & $2.41 \pm 0.31$ & $2.28 \pm 0.20^{\mathrm{a}}$ \\
\hline
\end{tabular}

Values are expressed as the mean \pm standard deviation. ${ }^{\mathrm{a}} \mathrm{P}<0.05$ vs. N. C, diabetic control group; E/A, early diastolic mitral valve blood flow velocity E peak/late diastolic mitral valve blood flow velocity A peak; IVS-d, diastolic interventricular septum thickness; LV, left ventricular; LVEF, LV ejection fraction; LVFS, LV fractional shortening; LVPW-d, diastolic LV posterior wall; LVPW-s, systolic LV posterior wall; $\mathrm{N}$, normal group; TMZ, trimetazidine.

Table II. Effect of TMZ on left ventricle mass indexes.

\begin{tabular}{lccc}
\hline Parameter & $\mathrm{N}(\mathrm{n}=9)$ & $\mathrm{C}(\mathrm{n}=8)$ & $\mathrm{TMZ}(\mathrm{n}=8)$ \\
\hline LVW/TH $(\mathrm{mg} / \mathrm{mg})$ & $0.719 \pm 0.025$ & $0.745 \pm 0.035^{\mathrm{a}}$ & $0.704 \pm 0.019^{\mathrm{b}}$ \\
LVW/BW (mg/g) & $2.0 \pm 0.31$ & $2.8 \pm 0.36^{\mathrm{c}}$ & $2.7 \pm 0.18^{\mathrm{c}}$ \\
BW (g) & $433 \pm 52$ & $248 \pm 50^{\mathrm{c}}$ & $232 \pm 57^{\mathrm{c}}$ \\
\hline
\end{tabular}

Values are expressed as the mean \pm standard deviation. ${ }^{\mathrm{a}} \mathrm{P}<0.05 \mathrm{vs} . \mathrm{N}$; ${ }^{\mathrm{b}} \mathrm{P}<0.01$ vs. $\mathrm{C} ;{ }^{\mathrm{c}} \mathrm{P}<0.001$ vs. N. BW, body weight; $\mathrm{C}$, diabetic control group; N, normal group; LVW/TH, left ventricular weight/total heart weight; TMZ, trimetazidine.

Table III. Effect of TMZ on hemodynamics parameters.

\begin{tabular}{lccc}
\hline Parameter & $\mathrm{N}(\mathrm{n}=7)$ & $\mathrm{C}(\mathrm{n}=8)$ & $\mathrm{TMZ}(\mathrm{n}=7)$ \\
\hline $\mathrm{LVSP}(\mathrm{mmHg})$ & $110 \pm 18$ & $87 \pm 15$ & $82 \pm 16$ \\
$\mathrm{LVEDP}(\mathrm{mmHg})$ & $0.1 \pm 2.9$ & $11.5 \pm 4.4^{\mathrm{a}}$ & $4.6 \pm 5.4^{\mathrm{b}}$ \\
$+\mathrm{dp} / \mathrm{dt}_{\max }(\mathrm{KPa} / \mathrm{sec})$ & $2425 \pm 701$ & $1892 \pm 427$ & $1937 \pm 695$ \\
dp $_{\mathrm{ddt}}(\mathrm{KPa} / \mathrm{sec})$ & $2379 \pm 546$ & $1481 \pm 533^{\mathrm{c}}$ & $1648 \pm 501$ \\
\hline
\end{tabular}

${ }^{\mathrm{a}} \mathrm{P}<0.001$ vs. $\mathrm{N}$; ${ }^{\mathrm{b}} \mathrm{P}<0.05$ vs. $\mathrm{C}$; ${ }^{\mathrm{c}} \mathrm{P}<0.05$ vs. $\mathrm{N} . \pm \mathrm{dp} / \mathrm{dt}$, maximum rates of increase and decrease in LV pressure; $\mathrm{C}$, diabetic control group; $\mathrm{N}$, normal group; LV, left ventricular; LVEDP, LV end dilated pressure; LVSP, LV systolic pressure; TMZ, trimetazidine.

$\mathrm{P}<0.05$, respectively). TMZ treatment decreased the LVEDP of diabetic rats $(\mathrm{P}<0.05)$. The exhaustive swimming test revealed that diabetic rats exhibited an impaired exercise capacity compared with their non-diabetic counterparts $(1273 \pm 170.80$ vs. $673.5 \pm 131.50 ; \mathrm{P}<0.05)$. However, TMZ treatment did not improve the exercise capacity of diabetic rats $(608$ 
A
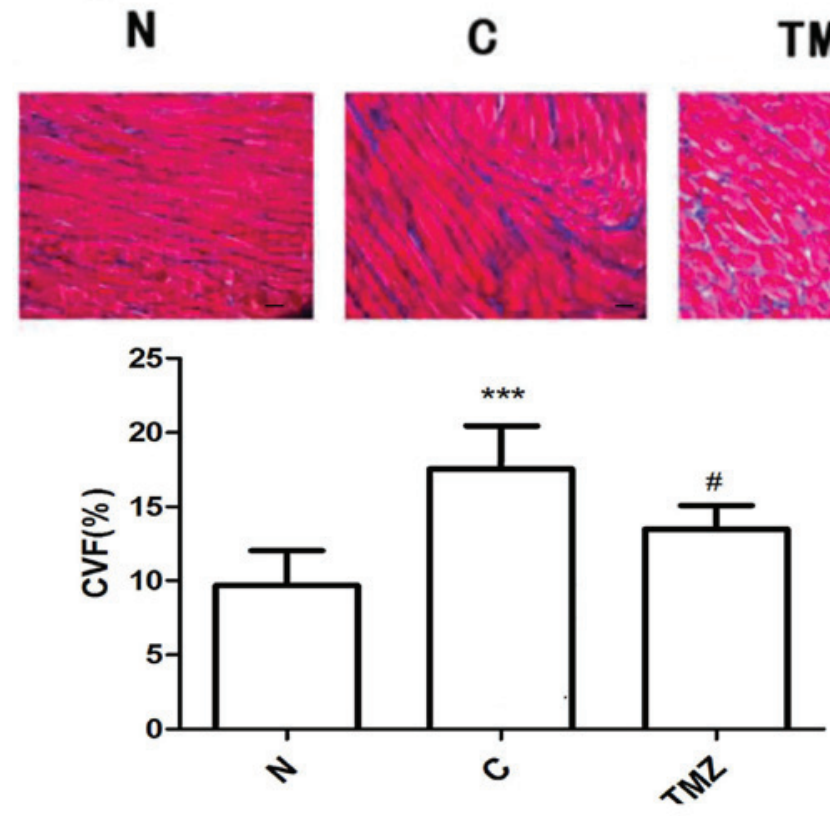

B

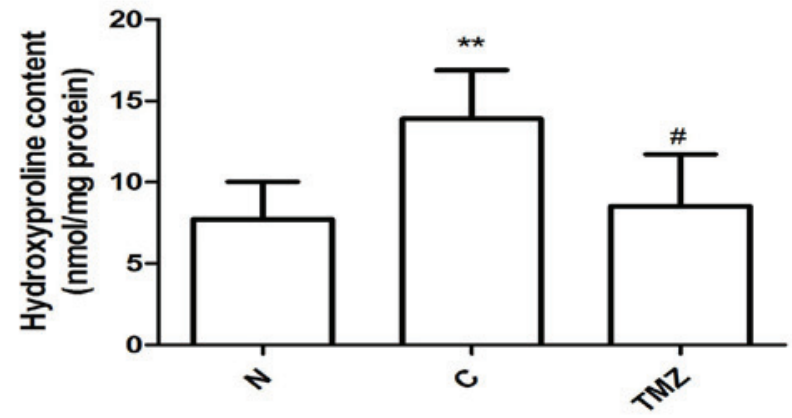

C

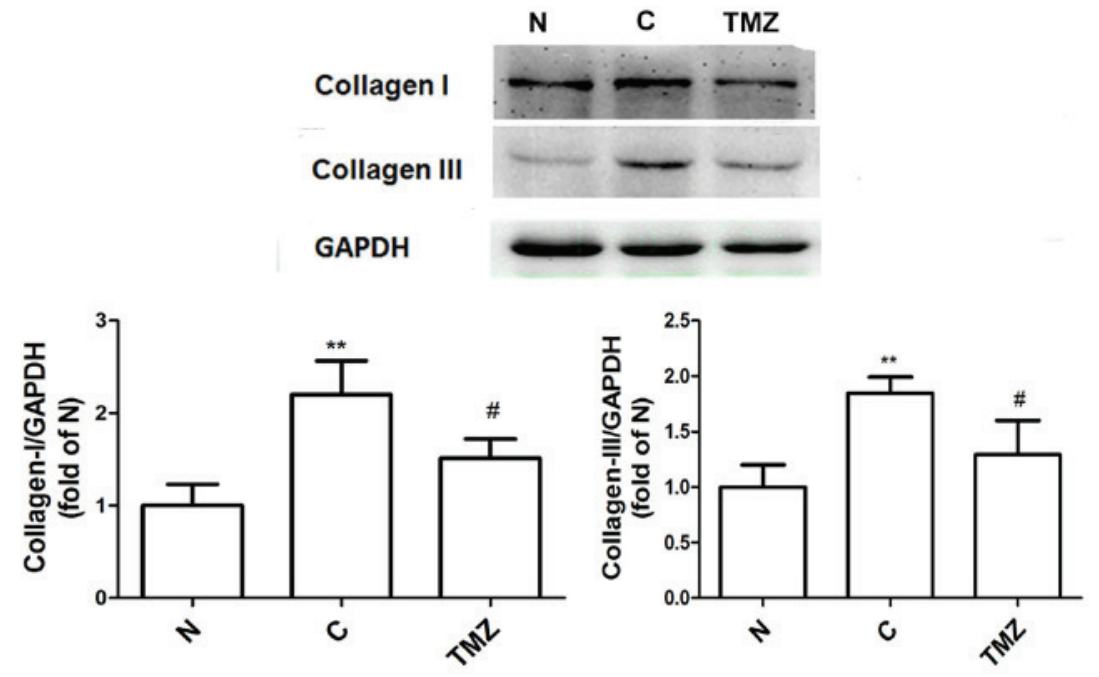

Figure 1. TMZ inhibits cardiac fibrosis in diabetic rats. (A) Masson staining of myocardial tissue from the different groups (magnification, x200; scale bar, $50 \mu \mathrm{m}$ ); (B) TMZ reduced the content of hydroxyproline in myocardial tissue. (C) Western blot analysis indicated that TMZ reduced the protein expression of collagen-I and collagen-III in myocardial tissue from diabetic rats. Values are expressed as the mean \pm standard deviation ( $\mathrm{n}=8$ animals/group). ${ }^{* * *} \mathrm{P}<0.01$ and ${ }^{* * * *} \mathrm{P}<0.01$ vs. $\mathrm{N} ;{ }^{*} \mathrm{P}<0.05$ vs. C. C, vehicle-treated diabetic group; $\mathrm{CVF}$, cardiac collagen volume fraction; $\mathrm{N}$, normal group; TMZ, trimetazidine.

$.50 \pm 170.80$ vs. $673.50 \pm 131.50, \mathrm{P}>0.05 ;$ Fig. S1). In conclusion, the 16 weeks of hyperglycemia caused significant changes in cardiac structure, cardiac function and exercise capacity; and subsequent TMZ treatment improved cardiac fibrosis and LV diastolic function in diabetic rats.
TMZ inhibits hyperglycemia-induced cardiac fibrosis and CTGF expression in myocardial tissue. Heart sections were stained with Masson's trichrome to determine the extent of interstitial fibrosis after 16 weeks. Morphologically, collagen deposition was increased in the $\mathrm{C}$ group but was attenuated in 


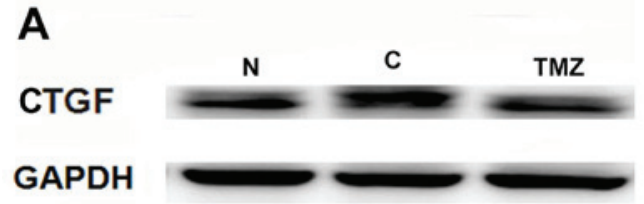

B
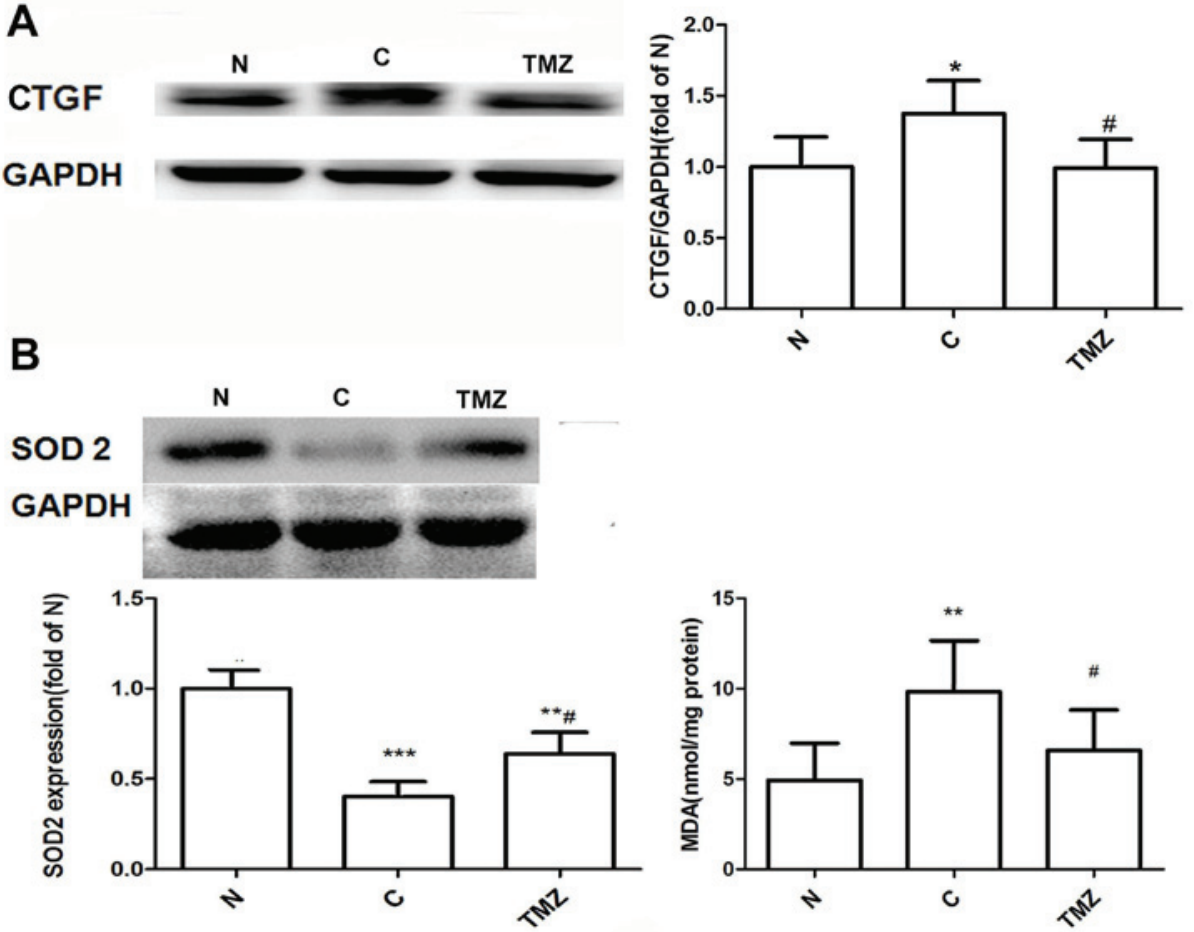

Figure 2. (A) TMZ reduced the protein expression of CTGF in myocardial tissue from diabetic rats. (B) Effects of TMZ on the protein expression of SOD-2 and on MDA content in myocardial tissue in each group. Values are expressed as the mean \pm standard deviation ( $\mathrm{n}=8$ animals/group). ${ }^{*} \mathrm{P}<0.05,{ }^{* * *} \mathrm{P}<0.01$ and ${ }^{* * * *} \mathrm{P}<0.01$ vs. N; "P<0.05 vs. C. C, vehicle-treated diabetic group; CFs, cardiac fibroblasts; CTGF, connective tissue growth factor; MDA, malondialdehyde; $\mathrm{N}$, normal group; TMZ, trimetazidine; SOD, superoxide dismutase.

the TMZ group (Fig. 1A). Quantitative evaluation of interstitial fibrosis in the heart by CVF indicated that TMZ markedly reduced intermuscular interstitial fibrosis by $23 \%$ in the diabetic rats compared with that in the diabetic rats treated with vehicle (Fig. 1A). Consistent with CVF, the LV hydroxyproline content was increased in the $\mathrm{C}$ group compared with the $\mathrm{N}$ group $(13.4 \pm 3.0$ vs. $7.2 \pm 2.3, \mathrm{P}<0.01$; Fig. $1 \mathrm{~B})$, whereas the content was significantly reduced in the TMZ group compared with the $\mathrm{C}$ group $(8.5 \pm 3.2$ vs. $13.4 \pm 3.0, \mathrm{P}<0.01$; Fig. $1 \mathrm{~B})$. The protein expression of $\mathrm{Col} \mathrm{I}$ and $\mathrm{Col}$ III was upregulated in the $\mathrm{C}$ group when compared with that in the $\mathrm{N}$ group (Col I: $2.2 \pm 0.37$ vs. $1.00 \pm 0.23, \mathrm{P}<0.01$; Col III: $1.85 \pm 0.15$ vs. $1.00 \pm 0.20$, $\mathrm{P}<0.01$; Fig. 1C). However, TMZ treatment downregulated the protein expression of $\mathrm{Col}$ I and $\mathrm{Col}$ III in diabetic rats compared with the $\mathrm{C}$ group (Col I: $1.5 \pm 0.41$ vs. $2.2 \pm 0.41, \mathrm{P}<0.05$; Col III: $1.29 \pm 0.31$ vs. $1.84 \pm 0.15, \mathrm{P}<0.05$; Fig. $1 \mathrm{C}$ ). The protein expression of CTGF was increased in the $\mathrm{C}$ group compared with that in the $\mathrm{N}$ group $(1.37 \pm 0.23$ vs. $1.00 \pm 0.22, \mathrm{P}<0.05)$. Compared with that in the $\mathrm{C}$ group, the protein expression of CTGF was downregulated in the TMZ group by $27.7 \%(0.99 \pm 0.20$ vs. $1.37 \pm 0.23$, $\mathrm{P}<0.05$; Fig. 2A).

Effect of TMZ on the protein expression of superoxide dismutase (SOD-2) and MDA levels in myocardial tissue. The protein expression of SOD-2 was downregulated in the $\mathrm{C}$ group compared with that in the $\mathrm{N}$ group $(0.40 \pm 0.12$ vs. $1.00 ; \mathrm{P}<0.001$; Fig. 2B). Compared with that in the $\mathrm{C}$ group, the protein expression of SOD-2 was upregulated in the TMZ group $(0.64 \pm 0.18$ vs. $0.40 \pm 0.12, \mathrm{P}<0.05$; Fig. $2 \mathrm{~B})$. MDA levels were increased in the $\mathrm{C}$ group compared with the $\mathrm{N}$ group
(9.8 \pm 2.8 vs. $4.9 \pm 2.2, \mathrm{P}<0.01)$, whereas it was decreased in the $\mathrm{TMZ}$ rats compared with the $\mathrm{C}$ group $(6.6 \pm 2.3$ vs. $9.8 \pm 2.8$, $\mathrm{P}<0.05$; Fig. 2B).TMZ inhibits $H G$-induced cardiac collagen synthesis in neonatal rat CFs. Immunofluorescence staining revealed that the purity of the isolated CFs was $>95 \%$ (Fig. 3A). The protein expression of Col I and Col III was significantly upregulated in the presence of HG $(1.92 \pm 0.20$ and $2.03 \pm 0.30$-fold of $\mathrm{NG}$, respectively) and downregulated by TMZ intervention (Fig. 3A). TMZ $(0.1 \mu \mathrm{M})$ decreased the protein levels of $\mathrm{Col}$ I by $44.3 \%$ (1.07 \pm 0.17 vs. $1.92 \pm 0.10$, $\mathrm{P}<0.01)$, and TMZ $(10 \mu \mathrm{M})$ decreased the protein levels of Col III by $48.5 \%(1.03 \pm 0.26$ vs. $2.03 \pm 0.30, \mathrm{P}<0.05$; Fig. 3B). The hydroxyproline content of the supernatant was increased in the HG group $(1.2 \pm 0.04$ vs. $1.00 \pm 0.03, \mathrm{P}<0.01)$, but was significantly decreased in the TMZ $(1 \mu \mathrm{M})$ group $(1.05 \pm 0.03$ vs. $1.2 \pm 0.04, \mathrm{P}<0.01$; Fig. $3 \mathrm{C})$.

TMZ inhibits HG-induced CTGF expression in neonatal rat CFs. The protein expression of CTGF increased 2.67-fold in the HG group compared with that in the NG group. However, TMZ $(1 \mu \mathrm{M})$ decreased the protein expression of CTGF by $37 \%$ in the diabetic rats (Fig. 4).

Effect of TMZ on ROS formation in neonatal rat CFs. ROS levels were evaluated using the ROS fluorescent dye DCFH-DA. CFs were exposed to HG $(25 \mathrm{mM})$ and normal glucose $(5.6 \mathrm{mM})$ for $24 \mathrm{~h}$. HG induced 1.84-fold increase of ROS, while ROS production decreased with TMZ treatment at 1 and $10 \mu \mathrm{M}(1.09 \pm 0.17$ and $0.97 \pm 0.29$ vs. $1.84 \pm 0.43$, $\mathrm{P}<0.05$; Fig. 5). 


\section{A Merge}

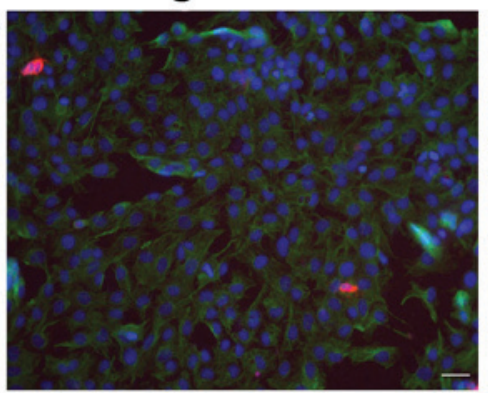

vWF

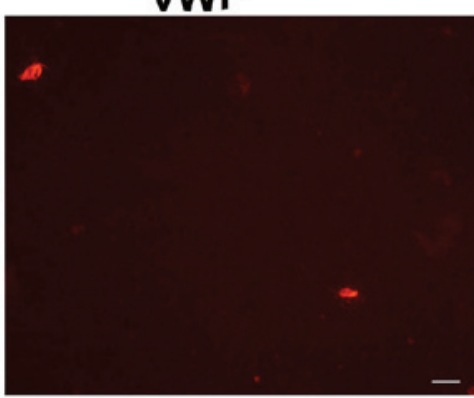

Vimentin

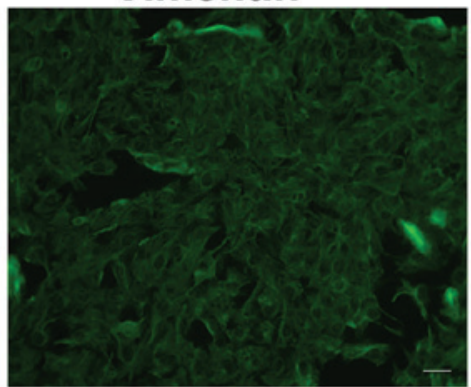

B
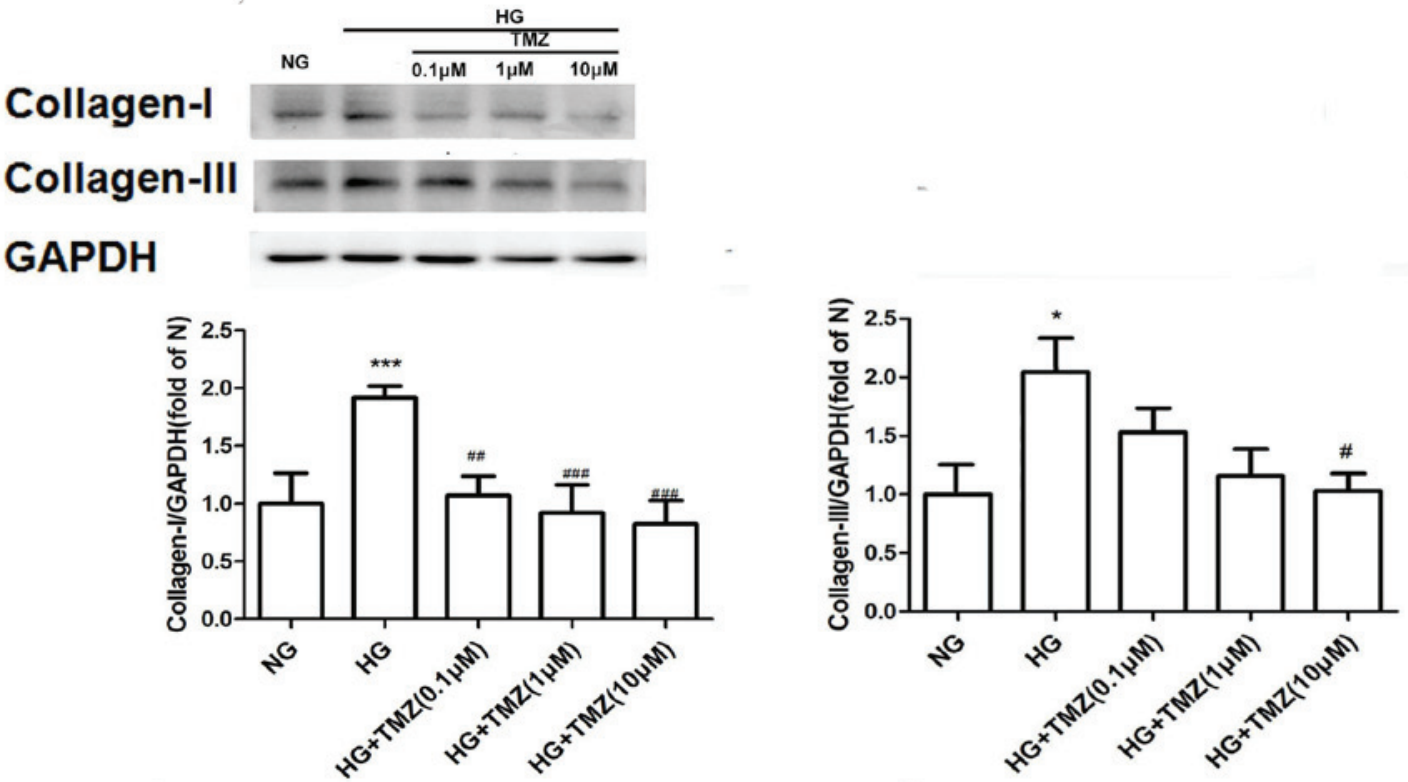

C

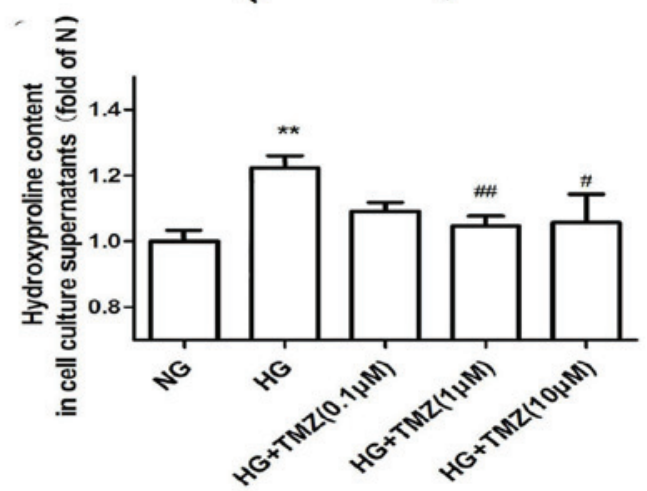

Figure 3. (A) Immunochemical stains for DAPI (blue), von Willebrand factor (red) and vimentin (green) for isolated CFs from 1-3 day old neonatal SD rats (fluorescence microscope, $\mathrm{x} 200$; scale bar, $50 \mu \mathrm{m}$ ). CFs were determined by positive staining for vimentin and negative staining for von Willebrand factor. The purity of the CFs was $>95 \%$. (B) TMZ reduced the protein expression of collagen-I and collagen-III in cardiac fibroblasts. (C) TMZ reduced the content of hydroxyproline in the cell supernatant. Values are expressed as the mean \pm standard deviation $(\mathrm{n}=3) .{ }^{*} \mathrm{P}<0.05,{ }^{* *} \mathrm{P}<0.01$ and ${ }^{* * * *} \mathrm{P}<0.001 \mathrm{vs} . \mathrm{NG} ;{ }^{\#} \mathrm{P}<0.05,{ }^{\# \#} \mathrm{P}<0.01$ and $^{\# \# \# P<0.001 ~ v s . ~ H G . ~ N G, ~ n o r m a l ~ g l u c o s e ; ~ H G, ~ h i g h ~ g l u c o s e ; ~ T M Z, ~ t r i m e t a z i d i n e . ~}$

\section{Discussion}

It is widely known that hyperglycemia increases the prevalence of ischemic heart disease (22). In recent years, the effect of hyperglycemia on non-ischemic heart disease has also been a major research hotspot. In the present study, STZ-induced diabetic rats presented with symptoms similar to those in humans with diabetes, including weight loss, polydipsia, polyuria and hyperglycemia in the first week of the study. In addition, they exhibited a reduction in LV systolic and diastolic function and a decrease in LV walls compared with those of normal rats after 4 months of the study, suggesting that STZ-induced diabetic rats have symptoms similar to those of diabetic cardiomyopathy. This rat model may therefore be used to simulate the heart conditions of diabetic patients.

Diabetes is a cardiac disease worth studying due to its association with metabolic abnormalities, which are independent of diabetic vascular complications. Diabetes leads to changes in carbohydrate metabolism, including impaired glucose uptake and reduced glycolysis and pyruvate 


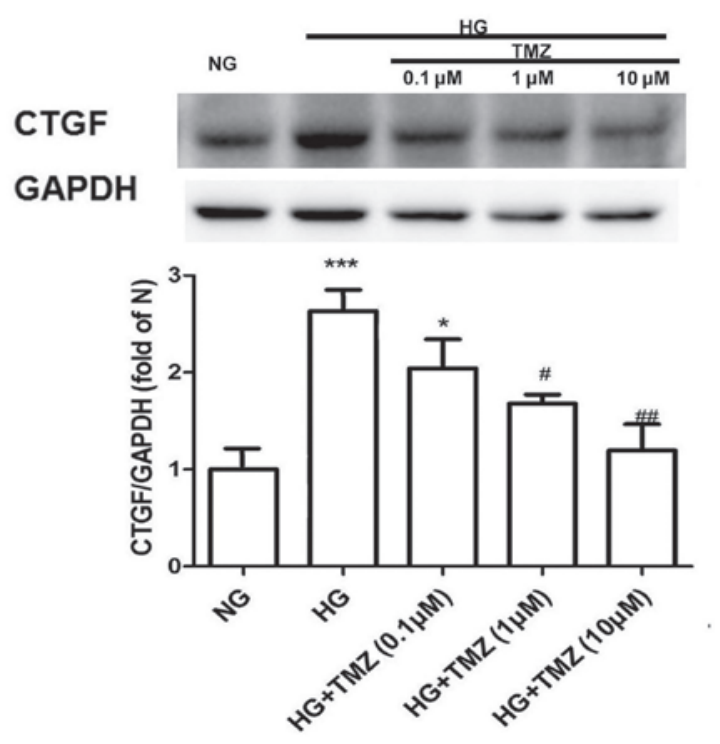

Figure 4. Trimetazidine reduced the protein expression of CTGF in cardiac fibroblasts. Values are expressed as the mean \pm standard deviation $(n=3)$. ${ }^{*} \mathrm{P}<0.05,{ }^{* * *} \mathrm{P}<0.001$ vs. NG; ${ }^{\#} \mathrm{P}<0.05,{ }^{\# \#} \mathrm{P}<0.01$ vs. HG. CTGF, connective tissue growth factor; HG, high glucose; NG, normal glucose; TMZ, trimetazidine.

oxidation (23). In contrast to glucose, fatty acid uptake is insulin-independent, which allows for an increase in fatty acids for myocardial oxidation in diabetes (23). In addition, the increase of ROS induced by hyperglycemia and excessive fatty acid oxidation leads to myocardial apoptosis and fibrosis, followed by eventual systolic and diastolic dysfunction of the LV (4,24,25). Metabolic therapies in diabetes may alleviate myocardial fibrosis and improve LV function.

TMZ, a long-chain fatty acid $\beta$-oxidative inhibitor, is thought to switch cardiac myocyte metabolism from FFA metabolism to glucose metabolism, thereby improving the myocardial oxidative metabolism effect (13). At the same time, numerous clinical trials have indicated that TMZ may improve cardiac function in patients with ischemic cardiomyopathy and heart failure (25-32). It also improves the heart function of patients with idiopathic dilated diabetes mellitus and it alleviates the increase in C-reactive protein and B-type natriuretic peptide to a certain extent (33).

In a study by Belardinelli et al (34), TMZ was able to improve endothelial function and reduce serum MDA and peroxide in chronic heart failure. However, studies on the influence of $\mathrm{TMZ}$ on diabetic cardiomyopathy are rare (35). In the present study, TMZ had no effect on heart rate, EF, FS, LV wall thickness, body weight, blood glucose, LV mass fraction or exercise tolerance. LVEDP is a good indicator of LV diastolic function. Considering that the LVFS and E/A lack sensitivity to the diastolic function in the rat heart, the hemodynamics of the model were further examined. TMZ was indicated to decrease LVEDP in patients with diabetes. In addition, the diabetic rats treated with $\mathrm{TMZ}$ had lower $\mathrm{LV} / \mathrm{TH}$ ratios. The present results suggest that TMZ has a role in alleviating ventricular remodeling and improving diastolic function in rats.

Pathological examination indicated that collagen deposition was more severe in diabetic rats than in non-diabetic rats.

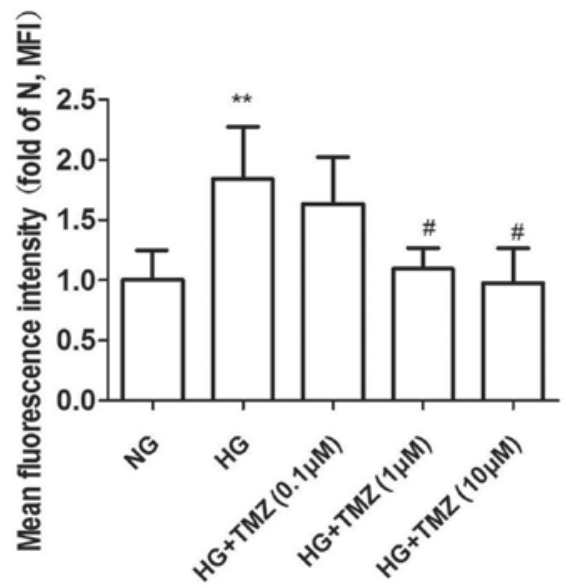

Figure 5. Effect of TMZ on reactive oxygen species production in neonatal rat cardiac fibroblasts. Values are expressed as the mean \pm standard deviation $(\mathrm{n}=3) .{ }^{* *} \mathrm{P}<0.01$ vs. NG; ${ }^{*} \mathrm{P}<0.05$ vs. HG. HG, high glucose; MFI, mean fluorescence intensity; NG, normal glucose; TMZ, trimetazidine.

In addition, TMZ decreased collagen deposition in diabetic rats. Western blot analysis of myocardial tissue revealed that $\mathrm{TMZ}$ reduced the levels of Col I and Col III in the myocardium of diabetic rats. It was also demonstrated that TMZ reduced collagen secretion in vitro. This result indicates that TMZ may reduce myocardial fibrosis in diabetic rats as one of the mechanisms to improve diastolic function.

Increases in ROS may lead to activation of multiple signaling pathways, resulting in cell fibrosis and death. Diabetes may cause myocardial fibrosis by increasing the levels of oxidative stress (36). Aragno et al (37) suggested that dehydroisoandrosterone improves cardiac fibrosis by reducing oxidative damage induced by high glycemia. In the present study, TMZ decreased the MDA level of myocardial tissue of the diabetic rat model in vivo and isolated rat CFs in vitro, and reduced the secretion of ROS in myocardial fibroblasts induced by hyperglycemia. This result is similar to that of McLennan et al (9), who reported that TMZ reduced the secretion of ROS in myocardial fibroblasts induced by angiotensin.

CTGF, a cell fibrosis factor, promotes fibroblast proliferation and interstitial collagen deposition. In patients with diabetes, CTGF has an important role in the development of cardiac fibrosis $(9,38)$. In the present study, TMZ was demonstrated to reduce the expression of the CTGF protein in myocardial tissue and myocardial fibroblasts in diabetic rats. TMZ may be used to reduce the production of myocardial fibroblast collagen to achieve an anti-fibrotic effect.

In conclusion, the present study demonstrated that diabetic rats with myocardial fibrosis have elevated LVEDP, LV/TH, CTGF protein expression and MDA levels at 16 weeks. Diabetic cardiomyopathy was associated with heart fibrosis and oxidative stress. TMZ may improve the diastolic function of diabetic rats. The effect may be associated with the reduction of ROS formation and CTGF expression in TMZ-treated rats. The present study suggests that TMZ may protect the heart of diabetic patients. In future studies, the association between ROS and CTGF, as well as the mechanism of TMZ to decrease ROS induced by HG, remain to be elucidated. 


\section{Acknowledgements}

Not applicable.

\section{Funding}

The present study was funded by The China Health Promotion Foundation.

\section{Availability of data and materials}

All data generated or analyzed during this study are included in this published article.

\section{Authors' contributions}

JL and YZ designed the experiment. YZ and YW performed the animal experiments. SHL and EQ performed the in vitro cell experiments. HZ and YL performed the echocardiography. JW, JZ and LP analyzed and interpreted the data. YZ and SL performed the histological examinations of the heart. $\mathrm{JL}$ and $\mathrm{YZ}$ were major contributors in writing the manuscript. All authors read and approved the final manuscript.

\section{Ethics approval and consent to participate}

The present study was performed in accordance with the Guide for the Care and Use of Laboratory Animals published by the US NIH (publication no. 85-23, revised 1996). All experimental protocols were approved by the Institutional Animal Care and Use Committee of Sun Yat-Sen University (IACUC-20140703).

\section{Patient consent for publication}

Not applicable.

\section{Competing interests}

The authors declare that they have no competing interests.

\section{References}

1. Shamhart PE, Luther DJ, Hodson BR, Koshy JC, Ohanyan V and Meszaros JG: Impact of type 1 diabetes on cardiac fibroblast activation: Enhanced cell cycle progression and reduced myofibroblast content in diabetic myocardium. Am J Physio Endocrinol Metab 297: E1147-E1153, 2009.

2. van Heerebeek L, Hamdani N, Handoko ML, Falcao-Pires I, Musters RJ, Kupreishvili K, Ijsselmuiden AJ, Schalkwijk CG, Bronzwaer JG, Diamant M, et al: Diastolic stiffness of the failing diabetic heart: Importance of fibrosis, advanced glycation end products, and myocyte resting tension. Circulation 117: 43-51, 2008.

3. Krenning G, Zeisberg EM and Kalluri R: The origin of fibroblasts and mechanism of cardiac fibrosis. J Cell Physiol 225: 631-637, 2010.

4. Bugyei-Twum A, Advani A, Advani SL, Zhang Y, Thai K, Kelly DJ and Connelly KA: High glucose induces Smad activation via the transcriptional coregulator p300 and contributes to cardiac fibrosis and hypertrophy. Cardiovas Diabetol 13: 89, 2014.

5. Dai B, Cui M, Zhu M, Su WL, Qiu MC and Zhang H: STAT1/3 and ERK1/2 synergistically regulate cardiac fibrosis induced by high glucose. Cell Physiol Biochem 32: 960-971, 2013.
6. Wahab NA, Weston BS and Mason RM: Connective tissue growth factor CCN2 interacts with and activates the tyrosine kinase receptor TrkA. J Am Soc Nephrol 16: 340-351, 2005.

7. Zhang J, Li PH, Yang L, Du QS, Guo TT and Tang X: Connective tissue growth factor mediates high glucose-induced down-regulation of podocalyxin expression in mouse podocytes. Nan Fang Yi ke Da Xue Xue Bao (Chinese) 31: 839-843, 2011.

8. Kobayashi T, Inoue T, Okada H, Kikuta T, Kanno Y, Nishida T, Takigawa M, Sugaya T and Suzuki H: Connective tissue growth factor mediates the profibrotic effects of transforming growth factor-beta produced by tubular epithelial cells in response to high glucose. Clin Exp Nephrol 9: 114-121, 2005.

9. McLennan SV, Wang XY, Moreno V, Yue DK and Twigg SM: Connective tissue growth factor mediates high glucose effects on matrix degradation through tissue inhibitor of matrix metalloproteinase type 1: Implications for diabetic nephropathy. Endocrinology 145: 5646-5655, 2004.

10. Matsuda S, Gomi F, Katayama T, Koyama Y, Tohyama M and Tano Y: Induction of connective tissue growth factor in retinal pigment epithelium cells by oxidative stress. Jpn J Ophthalmol 50: 229-234, 2006.

11. Matsuda S, Gomi F, Oshima Y, Tohyama M and Tano Y: Vascular endothelial growth factor reduced and connective tissue growth factor induced by triamcinolone in ARPE19 cells under oxidative stress. Invest Ophthalmol Vis Sci 46: 1062-1068, 2005.

12. Liu X, Gai Y, Liu F, Gao W, Zhang Y, Xu M and Li Z: Trimetazidine inhibits pressure overload-induced cardiac fibrosis through NADPH oxidase-ROS-CTGF pathway. Cardiovas Res 88: 150-158, 2010.

13. Kantor PF, Lucien A, Kozak R and Lopaschuk GD: The antianginal drug trimetazidine shifts cardiac energy metabolism from fatty acid oxidation to glucose oxidation by inhibiting mitochondrial long-chain 3-ketoacyl coenzyme A thiolase. Circ Res 86: 580-588, 2000.

14. Williams FM, Tanda K, Kus M and Williams TJ: Trimetazidine inhibits neutrophil accumulation after myocardial ischaemia and reperfusion in rabbits. J Cardiovas Pharmacol 22: 828-833, 1993.

15. Ruixing Y, Wenwu L and Al-Ghazali R: Trimetazidine inhibits cardiomyocyte apoptosis in a rabbit model of ischemia-reperfusion. Transl Res 149: 152-160, 2007.

16. Di Napoli P, Chierchia S, Taccardi AA, Grilli A, Felaco M, De Caterina $\mathrm{R}$ and Barsotti A: Trimetazidine improves post-ischemic recovery by preserving endothelial nitric oxide synthase expression in isolated working rat hearts. Nitric Oxide 16: 228-236, 2007.

17. Gajdosík A, Gajdosíkova A, Stefek M, Navarová J and Hozová R: Streptozotocin-induced experimental diabetes in male wistar rats. Gen Physiol Biophys 18 Spec No: 54-62, 1999.

18. Rennison JH, McElfresh TA, Okere IC, Vazquez EJ, Patel HV, Foster AB, Patel KK, Chen Q, Hoit BD, Tserng KY, et al: High-fat diet postinfarction enhances mitochondrial function and does not exacerbate left ventricular dysfunction. Am J Physiol Heart Circ Physiol 292: H1498-H506, 2007.

19. Luo J, Gao X, Peng L, Sun H and Dai G: Effects of hydrochlorothiazide on cardiac remodeling in a rat model of myocardial infarction-induced congestive heart failure. Eur J Pharmacol 667: 314-321, 2011.

20. Matsumoto K, Ishihara K, Tanaka K, Inoue K and Fushiki T: An adjustable-current swimming pool for the evaluation of endurance capacity of mice. J Appl Physiol (1985) 81: 1843-1849, 1996.

21. Fan YH, Dong H, Pan Q, Cao YJ, Li H and Wang HC: Notch signaling may negatively regulate neonatal rat cardiac fibroblast-myofibroblast transformation. Physiol Res 60: 739-748, 2011.

22. Morici ML, Di Marco A, Sestito D, Candore R, Cangemi C, Accardo F, Donatelli M, Cataldo MG and Lombardo A: The impact of coexistent diabetes on the prevalence of coronary heart disease. J Diabetes Complications 11: 268-273, 1997.

23. Isfort M, Stevens SC, Schaffer S, Jong CJ and Wold LE: Metabolic dysfunction in diabetic cardiomyopathy. Heart Fail Rev 19: 35-48, 2014.

24. Kumar D, Lou H and Singal PK: Oxidative stress and apoptosis in heart dysfunction. Herz 27: 662-668, 2002.

25. Yeung EH, Pankow JS, Astor BC, Powe NR, Saudek CD and Kao WH: Increased risk of type 2 diabetes from a family history of coronary heart disease and type 2 diabetes. Diabetes Care 30: 154-156, 2007. 
26. Fragasso G, Salerno A, Lattuada G, Cuko A, Calori G, Scollo A, Ragogna F, Arioli F, Bassanelli G, Spoladore R, et al: Effect of partial inhibition of fatty acid oxidation by trimetazidine on whole body energy metabolism in patients with chronic heart failure. Heart 97: 1495-500, 2011.

27. Fragasso G, Perseghin G, De Cobelli F, Esposito A, Palloshi A, Lattuada G, Scifo P, Calori G, Del Maschio A and Margonato A: Effects of metabolic modulation by trimetazidine on left ventricular function and phosphocreatine/adenosine triphosphate ratio in patients with heart failure. Eur Heart J 27: 942-948, 2006.

28. Belardinelli R, Cianci G, Gigli M, Mazzanti M and Lacalaprice F: Effects of trimetazidine on myocardial perfusion and left ventricular systolic function in type 2 diabetic patients with ischemic cardiomyopathy. J Cardiovasc Pharmacol 51: 611-615, 2008.

29. Belardinelli R, Lacalaprice F, Faccenda E and Volpe L: Trimetazidine potentiates the effects of exercise training in patients with ischemic cardiomyopathy referred for cardiac rehabilitation. Eur J Cardiovas Prev Rehabili 15: 533-540, 2008 .

30. El-Kady T, El-Sabban K, Gabaly M, Sabry A and Abdel-Hady S: Effects of trimetazidine on myocardial perfusion and the contractile response of chronically dysfunctional myocardium in ischemic cardiomyopathy: A 24-month study. Am J Cardiovasc Drugs 5: 271-278, 2005

31. Fragasso G, Palloshi A, Puccetti P, Silipigni C, Rossodivita A, Pala M, Calori G, Alfieri O and Margonato A: A randomized clinical trial of trimetazidine, a partial free fatty acid oxidation inhibitor, in patients with heart failure. J Am Coll Cardiol 48: 992-998, 2006.

32. Fragasso G, Piatti Md PM, Monti L, Palloshi A, Setola E, Puccetti P, Calori G, Lopaschuk GD and Margonato A: Shortand long-term beneficial effects of trimetazidine in patients with diabetes and ischemic cardiomyopathy. Am Heart J 146: E18, 2003.
33. Zhao P, Zhang J, Yin XG, Maharaj P, Narraindoo S, Cui LQ and Tang YS: The effect of trimetazidine on cardiac function in diabetic patients with idiopathic dilated cardiomyopathy. Life Sci 92: 633-638, 2013

34. Belardinelli R, Solenghi M, Volpe L and Purcaro A: Trimetazidine improves endothelial dysfunction in chronic heart failure: An antioxidant effect. Eur Heart J 28: 1102-1108, 2007.

35. Zhang L, Ding WY, Wang ZH, Tang MX, Wang F, Li Y, Zhong M, Zhang Y and Zhang W: Early administration of trimetazidine attenuates diabetic cardiomyopathy in rats by alleviating fibrosis, reducing apoptosis and enhancing autophagy. J Transl Med 14: $109,2016$.

36. Aragno M, Mastrocola R, Alloatti G, Vercellinatto I, Bardini P, Geuna S, Catalano MG, Danni O and Boccuzzi G: Oxidative stress triggers cardiac fibrosis in the heart of diabetic rats. Endocrinology 149: 380-388, 2008.

37. Aragno M, Meineri G, Vercellinatto I, Bardini P, Raimondo S, Peiretti PG, Vercelli A, Alloatti G, Tomasinelli CE, Danni O and Boccuzzi G: Cardiac impairment in rabbits fed a high-fat diet is counteracted by dehydroepiandrosterone supplementation. Life Sci 85: 77-84, 2009.

38. Wang X, McLennan SV, Allen TJ, Tsoutsman T, Semsarian C and Twigg SM: Adverse effects of high glucose and free fatty acid on cardiomyocytes are mediated by connective tissue growth factor. Am J Physiol Cell physiol 297: C1490-500, 2009.

This work is licensed under a Creative Commons Attribution-NonCommercial-NoDerivatives 4.0 International (CC BY-NC-ND 4.0) License. 